\title{
Stereoselective, Competitive, and Nonlinear Plasma Protein Binding of Ibuprofen Enantiomers as Determined in Vivo in Healthy Subjects
}

\author{
Jyoti K. Paliwal, ${ }^{1,2}$ David E. Smith,,${ }^{1,2,5}$ Steven R. Cox, ${ }^{3}$ \\ Rosemary R. Berardi, ${ }^{1}$ Valerie A. Dunn-Kucharski, ${ }^{1}$ and Grace H. Elta ${ }^{4}$
}

Received February 12, 1993-Final April 28, 1993

The plasma protein binding and competitive inhibition parameters of $\mathrm{R}(-)$ - and $\mathrm{S}(+)$-ibuprofen were determined in vivo in 12 healthy subjects. Subjects participated in a $4 \times 4$ Latin square design in which oral solutions of drug were administered as $300 \mathrm{mg} \mathbf{R}(-)$-ibuprofen, $300 \mathrm{mg} \mathbf{S}(+)$-ibuprofen, $300 \mathrm{mg} \mathbf{R}(-)$ - $+300 \mathrm{mg} \mathbf{S}(+)$-ibuprofen, and $300 \mathrm{mg} \mathbf{R}(-)-+600 \mathrm{mg} \mathrm{S}(+)$-ibuprofen. Unlabeled ibuprofen enantiomers were quantitated using a stereospecific reversed-phase HPLC assay, and plasma protein binding experiments were performed using radiolabeled ${ }^{I 4} \mathrm{C}$-enantiomers and an ultrafiltration method at 37C. At therapeutic drug concentrations, the protein binding of each enantiomer was greater than $99 \%$. Furthermore, the binding of ibuprofen enantiomers was stereoselective and mutually competitive, as well as nonlinear. The bound-free data were fitted to a model in which the nonlinearity of plasma protein binding and competition between enantiomers for binding sites could be accommodated. There were substantial differences in the affinity of ibuprofen enantiomers for protein binding sites ( $\mathrm{RP} 2=0.358 \pm 0.185$ vs. $\mathrm{SP} 2=0.979 \pm 0.501 \mu \mathrm{g} / \mathrm{ml} ; \overline{\mathrm{X}} \pm S D$ ) but no differences in their binding capacity ( $\mathrm{RP} 1=160 \pm 86$ vs. SP1 $=161 \pm 63 \mu \mathrm{g} / \mathrm{ml}$ ). Although statistically significant, the differences in competitive inhibition parameters were more modest ( $\mathrm{SKI}=0.661 \pm 0.363 v s . \mathrm{RKI}=0.436 \pm 0.210 \mu \mathrm{g} / \mathrm{ml}$ ). As a result, the intrinsic binding (i.e., $\mathrm{P} 1 / \mathrm{P} 2)$ of $\mathrm{R}(-)$-ibuprofen was greater than $\mathrm{S}(+)$-ibuprofen, and the unbound fraction was significantly greater for $\mathrm{S}$-enantiomer vs. R-enantiomer after a given dose of $\mathrm{R}$-ibuprofen or racemate.

KEY WORDS: ibuprofen enantiomers; plasma protein binding; stereoselectivity; competitive inhibition; nonlinearity; ultrafiltration.

This work was supported in part by a grant from The Upjohn Company, and by grants R01 GM 35498 and M01 RR00042 from the National Institutes of Health. During the course of this work, J. K. Paliwal was supported by a CONRAD Fellowship.

${ }^{1}$ College of Pharmacy, The University of Michigan, Ann Arbor, Michigan 48109-1065.

${ }^{2}$ Upjohn Center for Clinical Pharmacology, Medical School, The University of Michigan, Ann Arbor, Michigan.

${ }^{3}$ Clinical Pharmacokinetics Research Unit, The Upjohn Company, Kalamazoo, Michigan.

${ }^{4}$ Department of Internal Medicine, Medical School, The University of Michigan, Ann Arbor, Michigan.

${ }^{5}$ To whom correspondence should be addressed. 


\section{INTRODUCTION}

Ibuprofen is a prototype nonsteroidal anti-inflammatory drug (NSAID) of the arylpropionic acid class and, as such, is used for arthritic conditions in addition to its analgesic and antipyretic actions. However, despite the predominance of its use and numerous clinical studies, large gaps remain in our understanding of ibuprofen's pharmacokinetics and pharmacodynamics. Reasons for this lack of understanding reflect the fact that ibuprofen is administered as racemate even though its pharmacologic activities are associated primarily with the $S(+)$-enantiomer $(1,2)$. Furthermore, the pharmacokinetics of ibuprofen are complicated by a unidirectional $R$-to- $S$ chiral inversion as well as a stereoselectivity in drug disposition and plasma protein binding (3-6).

It is well recognized that plasma protein binding is a primary determinant of drug clearance for a compound of low hepatic extraction such as ibuprofen, and that differences in protein binding (e.g., as a function of disease or displacement) can have profound effects on the total drug concentrations observed in plasma $(7,8)$. However, human studies concerning the stereoselective binding of ibuprofen to plasma proteins are sparse $(6,9,10)$ and data on the protein binding parameters of $R(-)$ - and $S(+)$-ibuprofen and potential for enantiomeric competition in vivo are generally not available. As a result, those studies that have ignored the stereoselective aspects of ibuprofen protein binding, and its effect on drug metabolism and excretion are for the most part uninterpretable.

During our preliminary inspection of plasma data from healthy subjects in which the stereoselective kinetics of chiral inversion were to be evaluated, we observed that the protein binding of ibuprofen enantiomers appeared to be stereoselective and competitive, as well as nonlinear. Given the importance of this finding, we report here in detail the in vivo plasma protein binding parameters of each ibuprofen enantiomer alone and in the presence of its optical antipode.

\section{METHODS}

\section{Materials}

Unlabeled $R(-$ )-ibuprofen (Lot No. $25965 ; \geqslant 99 \%$ chemical purity, HPLC/UV) and unlabeled $S(+)$-ibuprofen (Lot No. 25966; $\geqslant 99 \%$ chemical purity, HPLC/UV) were available as sterile oral solutions of each enantiomer alone $(25 \mathrm{mg} / \mathrm{ml})$. Radiolabeled $R(-)$ [propionic acid-3 $-{ }^{14} \mathrm{C}$ ]ibuprofen (Lot No. 91-330-92-04; specific activity, $272 \mu \mathrm{Ci} / \mathrm{mg}$; $\geqslant 99 \%$ radiochemical purity, HPLC/Radiodetector) and radiolabeled $S(+)$ 
[propionic acid-3- ${ }^{14} \mathrm{C}$ ]-ibuprofen (Lot No. 91-330-92-03; specific activity, $255 \mu \mathrm{Ci} / \mathrm{mg} ; \geqslant 99 \%$ radiochemical purity, HPLC/Radiodetector) were available in ethanol at $534 \mu \mathrm{Ci} / \mathrm{ml}$ and $688 \mu \mathrm{Ci} / \mathrm{ml}$, respectively. Both unlabeled and radiolabeled enantiomers of ibuprofen were kindly donated by The Upjohn Company (Kalamazoo, MI).

\section{Study Design}

Selected for this study were 12 healthy subjects (Table I), 6 male and 6 female, between 20-29 years of age, and with a body weight within $\pm 15 \%$ of ideal values. Subjects were judged healthy, as determined by medical history, physical examination, and standard laboratory tests. In addition, subjects were nonsmokers and were medication- and alcohol-free during the study period. No subject was taking any known enzymeinducing or -inhibiting agent within 30 days of the study. All subjects were fully informed of the nature of the study and signed an informed consent form approved by the Committee to Review Grants for Clinical Research and Investigation Involving Human Beings of the University of Michigan Medical School. This study was performed in the General Clinical Research Center of the University of Michigan Hospitals.

Subjects participated in a $4 \times 4$ Latin square design in which ibuprofen was administered as enantiomer and as admixtures of varying proportions. Subjects were required to fast for at least $10 \mathrm{~h}$ prior to and for $4 \mathrm{~h}$ after each dose. Standard clinic meals including caffeine-free beverages were provided 4 and $10 \mathrm{~h}$ after dosing. No food or beverage other than water was consumed by the subjects except during the designated meal time.

Table I. Clinical Data of Healthy Subjects

\begin{tabular}{cccccc}
\hline Subject & Gender & $\begin{array}{c}\text { Age } \\
\text { (years) }\end{array}$ & $\begin{array}{c}\text { Weight } \\
(\mathrm{kg})\end{array}$ & $\begin{array}{c}\text { Serum protein } \\
(\mathrm{g} \%)\end{array}$ & $\begin{array}{c}\text { Serum albumin } \\
(\mathrm{g} \%)\end{array}$ \\
\hline 1 & M & 20 & 64.8 & 7.6 & 4.9 \\
2 & $\mathrm{~F}$ & 24 & 55.9 & 7.4 & 4.5 \\
3 & $\mathrm{~F}$ & 23 & 62.5 & 7.5 & 4.4 \\
4 & $\mathrm{~F}$ & 23 & 50.1 & 7.5 & 4.3 \\
5 & $\mathrm{~F}$ & 22 & 64.0 & 7.5 & 4.4 \\
6 & $\mathrm{M}$ & 21 & 66.9 & 8.3 & 4.9 \\
7 & $\mathrm{M}$ & 29 & 66.1 & 7.5 & 4.7 \\
8 & $\mathrm{M}$ & 20 & 79.9 & 7.8 & 4.7 \\
9 & $\mathrm{~F}$ & 25 & 76.1 & 7.0 & 4.2 \\
10 & $\mathrm{M}$ & 25 & 90.1 & 7.7 & 4.6 \\
11 & $\mathrm{~F}$ & 25 & 56.7 & 7.4 & 4.5 \\
12 & $\mathrm{M}$ & 23 & 82.3 & 8.1 & 5.1 \\
$\bar{X}( \pm \mathrm{SD})$ & & $23(3)$ & $68.0(11.9)$ & $7.6(0.3)$ & $4.6(0.3)$ \\
\hline
\end{tabular}


During the study, each subject received the following treatments as single oral doses with at least a 7-day washout period between each treatment: $300 \mathrm{mg} R(-)$-ibuprofen [300R], $300 \mathrm{mg} S(+)$-ibuprofen [300S], $300 \mathrm{mg} R(-)-+300 \mathrm{mg} S(-)$-ibuprofen [ $300 R+300 S$ ], and $300 \mathrm{mg} R(-)$ $+600 \mathrm{mg} S(+)$-ibuprofen $[300 R+600 S]$. Blood was drawn from a cephalic vein via an indwelling heparinized catheter $(10 \mathrm{U} / \mathrm{ml})$ and deposited into tubes containing EDTA. Seven milliliters of blood were drawn prior to dosing and at $0.75,1.5,14$, and $24 \mathrm{~h}$ after dosing. Ten milliliters of blood were drawn at $0.25,0.50,1,2,3,4,6,8,10$, and $12 \mathrm{~h}$ after dosing. Plasma was harvested soon after collection, immediately frozen, and stored at $\leqslant-20 \mathrm{C}$ until analyzed. Aliquots of plasma obtained from the $10-\mathrm{ml}$ blood samples were used in the plasma protein binding determinations.

\section{Analytical Methods}

Unlabeled ibuprofen enantiomers were quantitated in plasma using a stereospecific reversed-phase HPLC assay with ultraviolet detection (11) after minor modifications. Changes from the original procedure included the use of $S$-flurbiprofen as the internal standard and expanding the upper end of the concentration range from 20 to $50 \mu \mathrm{g} / \mathrm{ml}$. The assay was validated from 0.5 to $50 \mu \mathrm{g} / \mathrm{ml}$, and quality control samples $(1.00,4.01$, and $15.3 \mu \mathrm{g} / \mathrm{ml}$ of each enantiomer) were run over a 3-day period. Overall, the precision $(\% \mathrm{CV})$ and accuracy $(\%$ bias $)$ of the assay were $\leqslant 14.2$ and $\leqslant 7.6 \%$, respectively.

Radioactive measurements of ${ }^{14} \mathrm{C}$-ibuprofen enantiomers were performed on an LS 6000SC liquid scintillation counter (Beckman Instruments, Fullerton, CA) after mixing appropriate aliquots of plasma $(0.1 \mathrm{ml})$ or ultrafiltrate $(0.2 \mathrm{ml})$ with $4.5 \mathrm{ml}$ of Ready $\mathrm{Safe}^{\mathrm{TM}}$ scintillation cocktail (Beckman Instruments, Fullerton, CA). An external standard method was used for quench correction with a counting time of $20 \mathrm{~min}$ or $<2 \%$ error.

\section{Protein Binding}

The in vivo binding of $R(-)$ - and $S(+)$-ibuprofen to plasma proteins were determined by an ultrafiltration method. Samples were prepared by adding $8 \mu \mathrm{l}$ of radiolabeled ibuprofen enantiomer (after appropriate dilution with methanol) to $0.75 \mathrm{ml}$ of plasma so that counts were obtained in the region of $110,000 \mathrm{dpm} / \mathrm{ml}$. A $0.6 \mathrm{ml}$ aliquot was then introduced into a disposable Centrifree ${ }^{\mathrm{TM}}$ Micropartition System (Amicon Division, Beverly, MA) which utilizes a YMT ultrafiltration membrane (molecular weight 
cutoff, ca. 30,000), and the plasma sample was centrifuged at $1800 \times g$ in a fixed-angle rotor for $20 \mathrm{~min}$ at $37 \mathrm{C}$. Under these conditions, approximately $0.25 \mathrm{ml}$ of ultrafiltrate was obtained. Suitable aliquots of ultrafiltrate and prefiltered plasma were then subjected to liquid scintillation counting (LSC), as described above. Initial estimates for the unbound fraction were calculated as the ratio of ibuprofen enantiomer $(\mathrm{dpm} / \mathrm{ml})$ in ultrafiltrate and plasma, respectively. Unbound concentrations of ibuprofen enantiomer were then calculated as the unbound fraction multiplied by its respective total concentration of unlabeled drug in the original plasma sample; bound concentrations of ibuprofen enantiomer were calculated as the difference between total and unbound concentration in the original plasma sample.

It should be appreciated that each plasma sample was analyzed on two separate occasions, once with radiolabeled $R(-)$-ibuprofen and once with radiolabeled $S(+)$-ibuprofen. Preliminary mass balance studies indicated that ibuprofen enantiomers were not adsorbed to the membrane or ultrafiltration device and that leakage of plasma proteins was $<0.005 \%$, as determined using protein assay reagent (Bio-Rad Laboratories, Hercules, CA), human serum albumin standards (Sigma Chemical Co., St. Louis, MO), and the Bradford method (12). An additional purity check of the radiolabeled enantiomer was also made in which seven plasma standards (at $100 \mu \mathrm{g} / \mathrm{ml}$ for each enantiomer of ibuprofen plus radiolabeled drug) were subjected to this ultrafiltration method, and ultrafiltrate and prefiltered plasma were subsequently analyzed by LSC and by HPLC (13). Mean values $( \pm S D)$ for the unbound fraction were $0.833 \%( \pm 0.019)$ and $0.897 \%( \pm 0.091)$ for $R(-)$-ibuprofen after LSC and HPLC, respectively; the unbound fractions were $0.956 \%( \pm 0.070)$ and $0.889 \%( \pm 0.101)$ for $S(+)$-ibuprofen after LSC and HPLC, respectively. These values were within $\pm 8 \%$ of each other, and were not significantly different (paired or unpaired $t$ test; $\alpha=.05$ ).

\section{Data Analysis}

Data were pooled for each subject from the four treatment groups studied. As a result, 23 to 29 data pairs were available from three treatments for the bound vs. free plasma concentrations of $R(-)$-ibuprofen (i.e., $300 R, 300 R+300 S$, and $300 R+600 S$ ), and 32 to 38 data pairs were available from four treatments for the bound vs. free plasma concentrations of $S(+)$-ibuprofen (i.e., $300 R, 300 S, 300 R+300 S$, and $300 R+600 S$ ). In 22 out of 24 cases, the bound-free data were best fitted to a protein binding model that incorporates a single Langmuir term plus a competitive inhibition term such that 


$$
\begin{aligned}
& R C B=\frac{R P 1 \cdot R C F}{R P 2 \cdot(1+S C F / S K I)+R C F} \\
& S C B=\frac{S P 1 \cdot S C F}{S P 2 \cdot(1+R C F / R K I)+S C F}
\end{aligned}
$$

$R C B$ and $R C F$ are the respective bound and free plasma concentrations of $R(-)$-ibuprofen, $R P 1$ and $R P 2$ are binding parameters of $R(-)$-ibuprofen, $S C B$ and $S C F$ are the respective bound and free plasma concentrations of $S(+)$-ibuprofen, $S P 1$ and $S P 2$ are binding parameters of $S(+)$-ibuprofen, $R K I$ is the competitive inhibition parameter for $R$-enantiomeric effects on $S$-enantiomer binding, and $S K I$ is the competitive inhibition parameter for $S$-enantiomeric effects on $R$-enantiomer binding. However, in 2 out of 24 cases, the bound-free data of $R(-)$-ibuprofen were best fitted to a protein binding model that incorporates a single linear term (i.e., $R P 1 / R P 2$ ) plus a competitive inhibition term such that

$$
R C B=\frac{R P 1 / R P 2 \cdot R C F}{1+S C F / S K I}
$$

Binding parameters were obtained from Eqs. (1), (2), and (3) using the nonlinear least-squares regression program MINSQ (14) and a weighting factor of unity. In Eqs. (1) and (3), $R C B$ was the dependent variable and $R C F$ and $S C F$ were the independent variables. In Eq. (2), $S C B$ was the dependent variable and $S C F$ and $R C F$ were the independent variables. The quality of the fit was determined by evaluating the coefficient of determination, the standard deviation of parameter estimates and data, and by the visual inspection of residuals. Other protein binding models were attempted (e.g., competitive Langmuir term plus a linear term). However, the additional complexity of the models were beyond what the in vivo data would allow.

To compensate for random fluctuations in the ultrafiltration data, fitted values of unbound enantiomer, $R \hat{C} F$ (or $S \hat{C} F$ ) could be obtained by finding the positive root of quadratic Eqs. (4) and (5) below for a given value of $S C F$ (or $R C F$ ) and the respective total concentration of $R$-enantiomer, $R C P$ (or $S$-enantiomer, $S C P$ ) in the original plasma sample (15). As such

$$
\begin{aligned}
& R \hat{C} F^{2}+[R P 1+R P 2 \cdot(1+S C F / S K I)-R C P] \cdot R \hat{C} F \\
& \quad-R P 2 \cdot(1+S C F / S K I) \cdot R C P=0 \\
& S \hat{C} F^{2}+[S P 1+S P 2 \cdot(1+R C F / R K I)-S C P] \cdot S \hat{C} F \\
& \quad-S P 2 \cdot(1+R C F / R K I) \cdot S C P=0
\end{aligned}
$$


for those cases in which protein binding was nonlinear and competitive, i.e., corresponds to Eqs. (1) and (2). For those cases in which protein binding was linear and competitive, i.e., corresponds to Eq. (3), fitted values of unbound $R$-enantiomer could be calculated in a simpler fashion as

$$
R \hat{C} F=\frac{R C P}{1+\frac{R P I / R P 2}{1+S C F / S K I}}
$$

These fitted unbound concentrations $(R \hat{C} F$ and $S \hat{C} F$ ) were used for subsequent calculations of area under the curve and for final estimates of the unbound fraction (individual and time-averaged). Area under the unbound plasma concentration-time curve for $R(-)$ - and $S(+)$-ibuprofen $(R . A U C, u$ and $S . A U C, u$ ) was calculated using a combination of the linear and log-trapezoidal rules, extrapolated to infinity by CFlast/ $\lambda$ n. CFlast is the last measurable unbound plasma concentration and $\lambda n$ is determined by linear regression of data points from the log-linear terminal phase. Area under the total plasma concentration-time curve $(R . A U C$ and $S . A U C)$ was determined in an analogous manner using total concentrations of ibuprofen enantiomer. And finally, the time-averaged unbound fraction for $R(-)$ -

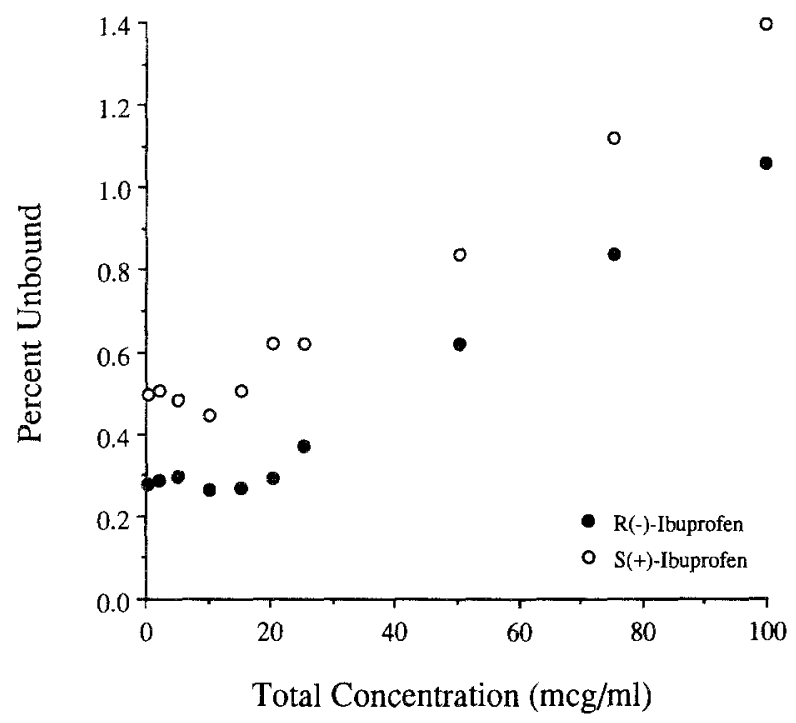

Fig. 1. Relationship between percentage unbound and total plasma concentration of ibuprofen enantiomers, as determined in vitro using spiked plasma samples of each enantiomer alone and an ultrafiltration method at $37 \mathrm{C}$. 
and $S(+)$-ibuprofen $(R . F u$ and $S . F u)$ was calculated as the $A U C, u / A U C$ ratio of each enantiomer.

In this analysis, no correction was made for the contribution of label to the total plasma concentration of ibuprofen enantiomer. This was unnecessary since the radiolabeled enantiomer $(0.2 \mu \mathrm{g} / \mathrm{ml})$ was negligible in relation to the total plasma concentration at which nonlinear protein binding becomes important (i.e., $C P \geqslant 15 \mu \mathrm{g} / \mathrm{ml}$; Fig. 1). This finding was consistent with our in vivo data as well as with observations by other investigators (6). Further, this method of data analysis resulted in $A U C$ (and $F u$ ) determinations that were, on average, within 2 and $5 \%$ of those values obtained with nonfitted data for $R(-)$-ibuprofen and $S(+)$-ibuprofen, respectively.

Data are reported as mean $( \pm S D)$ unless otherwise indicated. For each enantiomer, statistical differences were determined between treatments $(300 R, 300 R+300 S, 300 R+600 S$ for $R(-)$-ibuprofen; $300 R, 300 S$, $300 R+300 S, 300 R+600 S$ for $S(+)$-ibuprofen) using ANOVA for a Latin square study, with treatments, periods, and subjects as fixed effects $(x=.05)$. Pairwise comparisons were then made using Tukey's test. Significant differences were determined between enantiomers using a paired $t$ test $(\alpha=.05)$.

\section{RESULTS}

In evaluating the plasma protein binding data of ibuprofen enantiomers, it was observed that the bound-free relationship of $R(-)$ ibuprofen was substantially shifted to the right as the amount of $S$-enantiomer increased (Fig. 2, top panel). A similar relationship was observed for $S(+)$-ibuprofen while in the presence of increasing amounts of $R(-)$-enantiomer, however, the shift was less pronounced (Fig. 2, bottom panel). This interaction was consistent for both enantiomers in all 12 subjects and appeared to be one of a competitive nature. The observed but smaller shift for $S(+)$-ibuprofen data is a consequence of this particular study design in which $R$-enantiomer doses were not as varied as for the $S$-enantiomer. These figures also demonstrate the nonlinear protein binding of ibuprofen enantiomers after a typical $600-\mathrm{mg}$ dose of racemate.

Based on this observation, ibuprofen enantiomers were fitted to a model in which the nonlinearity of plasma protein binding and competition between enantiomers for binding sites could be accommodated. As shown in Table II, this model was able to provide estimates for the binding parameters of $R(-)$-ibuprofen in 10 out of 12 subjects, and for the binding parameters of $S(+)$-ibuprofen in 12 out of 12 subjects. However, in 2 subjects the binding parameters of $R(-)$-ibuprofen were better estimated using a linear model with a competitive inhibition term. Regardless, the data 

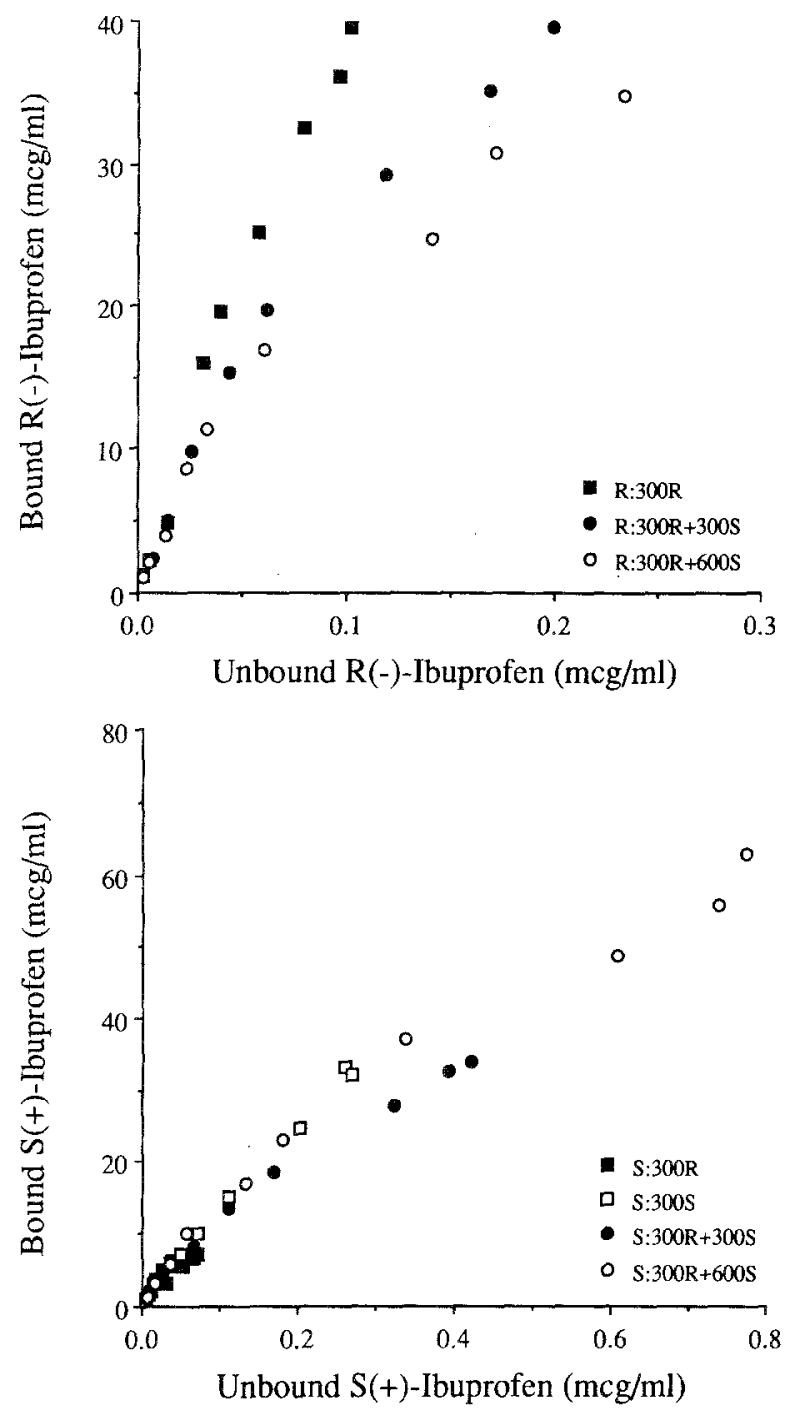

Fig. 2. Bound-free relationship of $R(-)$-ibuprofen plasma concentrations in a representative healthy subject, as determined in vivo using experimentally derived plasma samples and an ultrafiltration method at $37 \mathrm{C}$ (top panel); bound-free relationship of $S(+)$-ibuprofen plasma concentrations in the same healthy subject (bottom panel). Subjects received each treatment according to a Latin square design in which oral solutions of drug were administered as $300 \mathrm{mg} R(-)$-ibuprofen $[300 R], 300 \mathrm{mg}$ $S(+)$-ibuprofen [300S], $300 \mathrm{mg} R(-)$ - $+300 \mathrm{mg} S(+)$-ibuprofen $[300 R+300 S]$, and $300 \mathrm{mg} \mathrm{R}(-)-+600 \mathrm{mg} \mathrm{S}(+)$-ibuprofen $[300 R+600 S]$. 
Table II. Plasma Protein Binding and Competitive Inhibition Parameters of $R(-)$ - and $S(+)$-Ibuprofen

\begin{tabular}{|c|c|c|c|c|c|c|c|}
\hline \multirow[b]{2}{*}{ Subject } & \multicolumn{4}{|c|}{ Binding parameters of $R(-)$-ibuprofen ${ }^{a}$} & \multicolumn{3}{|c|}{ Measures of fit ${ }^{b}$} \\
\hline & $R P I(\mu \mathrm{g} / \mathrm{ml})$ & $R P 2(\mu \mathrm{g} / \mathrm{ml})$ & $S K I(\mu \mathrm{g} / \mathrm{ml})$ & $R P I / R P 2$ & $r^{2}$ & Corr & $M S C$ \\
\hline 1 & $125(30)$ & $0.292(0.083)$ & $0.717(0.093)$ & 428 & .986 & .993 & 4.014 \\
\hline 2 & $63.8(6.7)$ & $0.124(0.020)$ & $1.35(0.43)$ & 515 & .984 & .992 & 3.882 \\
\hline 3 & $88.6(9.1)$ & $0.218(0.031)$ & $1.42(0.25)$ & 406 & .992 & .996 & 4.572 \\
\hline 4 & $195(49)$ & $0.362(0.106)$ & $0.391(0.027)$ & 539 & .990 & .995 & 4.362 \\
\hline 5 & $303(184)$ & $0.669(0.438)$ & $0.332(0.030)$ & 453 & .984 & .992 & 3.917 \\
\hline 6 & $113(17)$ & $0.291(0.056)$ & $0.587(0.078)$ & 388 & .990 & .995 & 4.329 \\
\hline 7 & $218(78)$ & $0.475(0.206)$ & $0.467(0.082)$ & 459 & .982 & .991 & 3.796 \\
\hline 8 & - & - & $0.548(0.048)$ & $385(10)$ & .984 & .992 & 3.986 \\
\hline 9 & $67.2(10.2)$ & $0.146(0.031)$ & $0.773(0.180)$ & 460 & .978 & .989 & 3.579 \\
\hline 10 & - & - & $0.369(0.046)$ & $442(15)$ & .971 & .985 & 3.393 \\
\hline 11 & $280(110)$ & $0.618(0.284)$ & $0.483(0.054)$ & 453 & .980 & .990 & 3.672 \\
\hline 12 & $144(34)$ & $0.389(0.107)$ & $0.492(0.056)$ & 370 & .989 & .995 & 4.242 \\
\hline $\bar{X} \pm \mathrm{SD}$ & $160 \pm 86$ & $0.358 \pm 0.185$ & $0.661 \pm 0.363$ & $442 \pm 51$ & & & \\
\hline
\end{tabular}

Binding parameters of $S(+)$-ibuprofen ${ }^{a}$

\begin{tabular}{clllllll}
\cline { 2 - 5 } & $S P 1(\mu \mathrm{g} / \mathrm{ml})$ & $S P 2(\mu \mathrm{g} / \mathrm{ml})$ & $R K I(\mu \mathrm{g} / \mathrm{ml})$ & $S P 1 / S P 2$ & & & \\
\hline 1 & $103(11)$ & $0.533(0.065)$ & $0.844(0.453)$ & 193 & .993 & .997 & 4.841 \\
2 & $114(10)$ & $0.802(0.088)$ & $0.789(0.171)$ & 142 & .995 & .998 & 5.070 \\
3 & $225(32)$ & $1.47(0.23)$ & $0.362(0.033)$ & 153 & .997 & .999 & 5.487 \\
4 & $298(105)$ & $2.18(0.83)$ & $0.435(0.082)$ & 137 & .988 & .994 & 4.225 \\
5 & $104(10)$ & $0.642(0.077)$ & $0.314(0.032)$ & 162 & .995 & .998 & 5.158 \\
6 & $122(16)$ & $0.563(0.092)$ & $0.262(0.040)$ & 217 & .989 & .994 & 4.295 \\
7 & $146(24)$ & $0.737(0.140)$ & $0.262(0.043)$ & 198 & .990 & .995 & 4.437 \\
8 & $209(58)$ & $1.29(0.38)$ & $0.173(0.020)$ & 162 & .992 & .997 & 4.706 \\
9 & $130(17)$ & $0.708(0.107)$ & $0.325(0.053)$ & 184 & .993 & .997 & 4.845 \\
10 & $123(16)$ & $0.706(0.108)$ & $0.376(0.080)$ & 174 & .992 & .996 & 4.734 \\
11 & $229(44)$ & $1.41(0.29)$ & $0.505(0.105)$ & 162 & .995 & .998 & 5.143 \\
12 & $125(30)$ & $0.710(0.183)$ & $0.588(0.292)$ & 176 & .982 & .992 & 3.846 \\
$\bar{X} \pm \mathrm{SD}$ & $161 \pm 63$ & $0.979 \pm 0.501$ & $0.436 \pm 0.210$ & $172 \pm 24$ & & &
\end{tabular}

Significance $^{c} \quad p=0.9959 \quad p=0.0066 \quad p=0.0481 \quad p<0.0001$

${ }^{a}$ Values in parentheses represent the standard error of individual parameter estimates.

${ }^{b} r^{2}$ is the coefficient of determination, Corr is the correlation between observed and predicted bound concentrations of ibuprofen enantiomer, and $M S C$ is the Model Selection Criterion (14).

'Statistical differences (i.e., $R P l$ vs. $S P I, R P 2$ vs. $S P 2, S K I$ vs. $R K I$, and $R P 1 / R P 2$ vs. $S P 1 / S P 2)$ were determined by paired $t$ test.

were described reasonably well overall, as indicated by the measures of tit and standard deviations of the estimated parameters shown in Table II. On average, there were substantial differences in the affinity of ibuprofen enantiomers for protein binding sites $(R P 2=0.358$ vs. $S P 2=0.979 \mu \mathrm{g} / \mathrm{ml}$; $p=0.0066)$ but no differences in their binding capacity ( $R P l=160$ vs. 


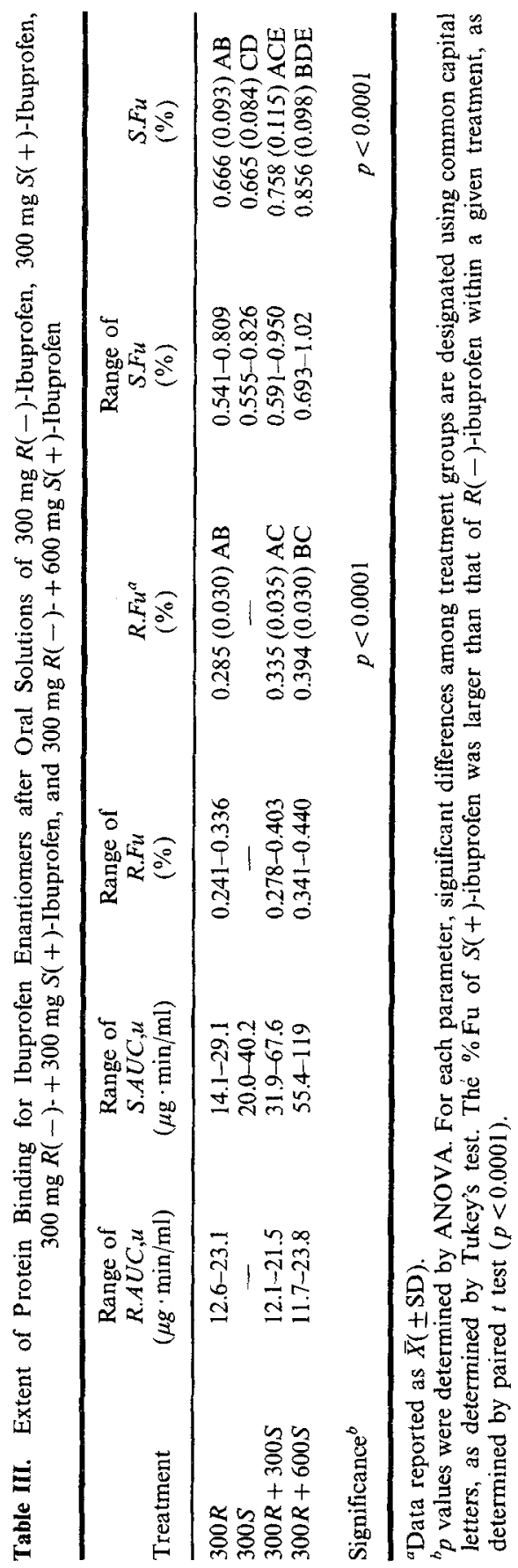


$S P I=161 \mu \mathrm{g} / \mathrm{ml} ; \quad p=0.9959)$. Although significant, the differences in competitive inhibition parameters were more modest ( $S K I=0.661$ vs. $R K I=0.436 \mu \mathrm{g} / \mathrm{ml} ; P=0.0481$ ). As a result, under linear conditions and in the absence of a competitor, the intrinsic binding of $R(-)$-ibuprofen was two- to threefold greater than that of $S(+)$-ibuprofen $(R P 1 / R P 2=442$ vs. $S P 1 / S P 2=172 ; p<0.0001)$.

In Table III, areas under the curve for unbound enantiomer $(A U C, u)$ and values for the time-averaged unbound fraction $(F u)$ are provided with respect to the actual treatments administered. As shown in this table, the range of values for $R . A U C, u$ were very similar between the three treatments in which $R(-)$-ibuprofen could be measured. And as expected, the range of values for $S . A U C, u$ increased in a monotonic fashion as increasing amounts of $S(+)$-ibuprofen were dosed in these four treatments. Based on the $A U C, u$ for both enantiomers, the range and mean values for unbound fraction also changed as a function of treatment. The unbound fraction of $R(-)$-ibuprofen was significantly different between all three pairwise comparisons $(p<0.0001)$, and $R . F u$ was $38 \%$ greater when administered as $300 R+600 S$ vs. $300 R$. This increase reflects the competitive displacement of $R(-)$-ibuprofen by $S(+)$-ibuprofen since $A U C, u$ values are unchanged for $R$-enantiomer but substantially increased for $S$-enantiomer. With respect to the unbound fraction of $S(+)$-ibuprofen, five out of six pairwise comparisons were significantly different $(p<0.0001)$, and S.Fu was $29 \%$ greater when administered as $300 R+600 S$ vs. $300 S$. In this case, the increase is primarily due to the nonlinearity in protein binding produced by $S$-enantiomer since unbound drug concentrations of $R(-)$-ibuprofen do not accumulate to the same extent. It is interesting that values for $S . F u$ are the same after $300 R$ and $300 S$ treatments. This probably reflects an effect of the competitive inhibitor $R(-)$-ibuprofen being present with the lower levels of unbound $S$-enantiomer in the $300 R$ treatment. And finally, the time-averaged unbound fraction of $S(+)$-ibuprofen was at least twofold greater than that of $R(-)$-ibuprofen for the three treatments in which they were compared. After a typical $600-\mathrm{mg}$ dose of racemate, the extent of plasma protein binding was $99.665 \%$ for $R(-)$-ibuprofen (mean $R C P \leqslant 29.6 \mu \mathrm{g} / \mathrm{ml}$ ) and $99.242 \%$ for $S(+)$ )ibuprofen (mean $S C P \leqslant 29.0 \mu \mathrm{g} / \mathrm{ml})$.

\section{DISCUSSION}

Ibuprofen is a compound of low hepatic extraction and, as such, plasma protein binding is a primary determinant of the drug's total clearance and plasma concentrations. Based on theory, changes in the unbound fraction would not be expected to change ibuprofen's unbound 
clearance nor its pharmacologically active unbound species. This outcome has been shown experimentally where 15 subjects showed a nonlinear relationship between dose and $A U C$ for total plasma concentrations of drug (7). In contrast, the $A U C, u$ of ibuprofen was linearly related to the dose suggesting that oral clearance was dose-independent when based on unbound drug. However, this relationship may not hold if the elimination pathways of ibuprofen are capacity rate-limited (e.g., due to disease, displacement, or age). In addition, one must consider the plasma protein binding of ibuprofen enantiomers in order to correctly interpret dose-response relationships as well as mechanistic data on the drug's stereoselective metabolism or chiral inversion kinetics $(4,5)$.

Data on the stereoselective aspects of ibuprofen plasma protein binding have been rather limited $(6,9,10)$. Using an equilibrium dialysis method, Evans et al. (10) found the unbound fraction to increase from 0.296 to $0.461 \%$ for $R(-)$-ibuprofen and from 0.484 to $0.668 \%$ for $S(+)$-ibuprofen as racemic doses were increased from 200 to $1200 \mathrm{mg}$ in four healthy male subjects. They also reported that at each dose level, the unbound fraction in plasma was significantly greater for the $S(+)$-enantiomer. In a second study (9), these same authors reported the unbound fraction of $R(-)$ - and $S(+)$-ibuprofen as 0.419 and $0.643 \%$, respectively, in six healthy male subjects with no effect of cimetidine on protein binding. However, it should be appreciated that in these two studies, time-averaged values for the unbound fraction were based upon the $A U C$ from only five or six plasma samples. And finally, Evans et al. (6) observed that the percentage unbound of each ibuprofen enantiomer was concentration-dependent over the therapeutic range and was influenced by the presence of its optical antipode. Still, this final observation was obtained from in vitro data and, as a whole, no information is available on the binding parameters of ibuprofen enantiomers and potential for competitive inhibition in the in vivo setting.

In this study, we provide in vivo data on the extent of plasma protein binding as well as estimates for the binding and competitive inhibition parameters of $R(-)$ - and $S(+)$-ibuprofen in 12 healthy subjects. Consistent with plasma protein binding studies using ibuprofen racemate (16), more than $99 \%$ of each enantiomer was protein-bound after therapeutic doses of drug. However, stereoselective differences were observed between ibuprofen enantiomers in their binding affinity and in their competitive inhibitory potential. No difference was observed, however, in the binding capacity as a function of chirality. As a result, the intrinsic binding of $R(-)$-ibuprofen was greater than $S(+)$-ibuprofen, and the unbound fraction was significantly greater for $S$-enantiomer vs. $R$-enantiomer in all relevant treatment comparisons. It is also apparent that the binding of 

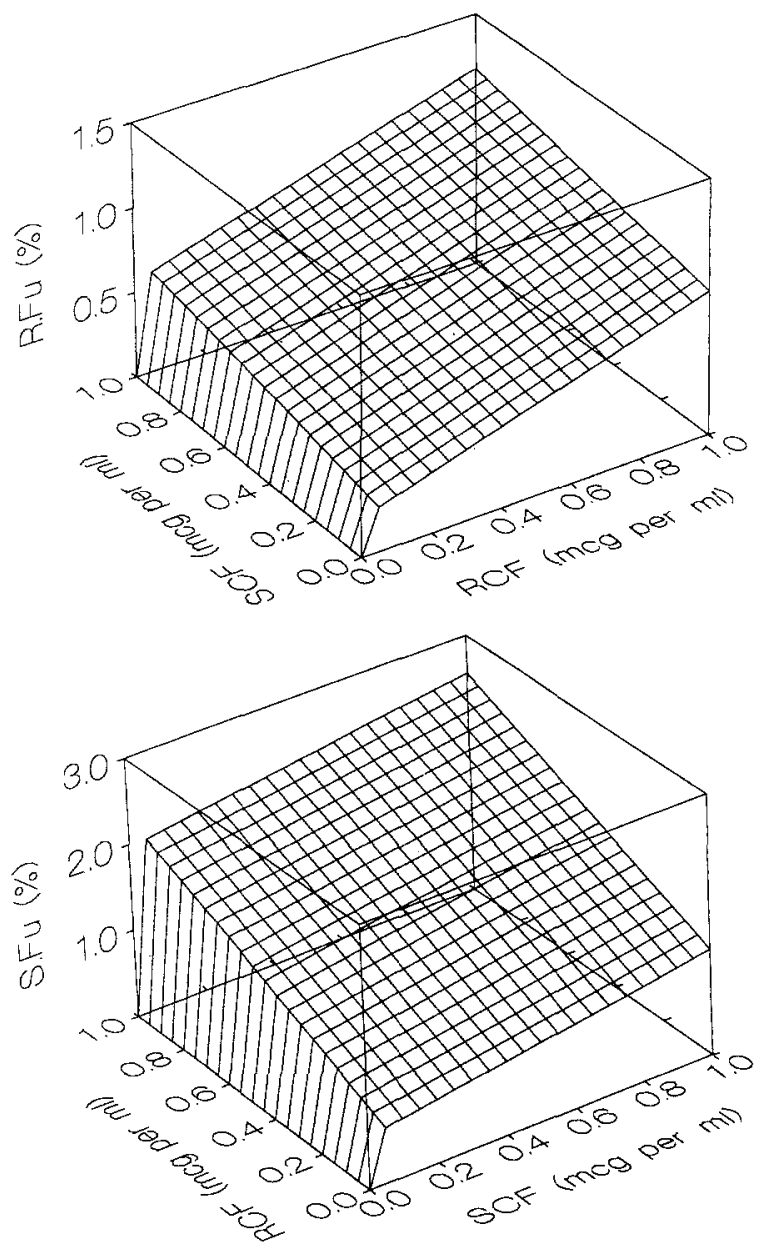

Fig. 3. Three-dimensional plot illustrating the nonlinear binding of $R(-)$-ibuprofen and the competitive displacement by its $S$-enantiomer (top panel); nonlinear binding of $S(+)$-ibuprofen and the competitive displacement by its $R$-enantiomer (bottom panel). Data were simulated for each enantiomer using the mean values for binding capacity, and the equilibrium association and competitive inhibition constants in Table II.

either enantiomer is reduced by the presence of its optical antipode. Using mean data for the binding capacities, affinity constants, and competitive inhibition parameters (Table II), the plasma protein binding for $R(-)$-and $S(+)$-ibuprofen could be summarized in the 3D-plots depicted in Fig. 3 (top and bottom panels, respectively). After $600 \mathrm{mg}$ or less of ibuprofen 
racemate, values for the unbound fraction of either enantiomer are confined to the gridlines of the lower left quadrant.

As reviewed by Lin et al. (8), four conditions are required for a significant competitive displacement from plasma proteins to occur. First, the displaced drug should be highly protein-bound. Second, the displacer should occupy the same binding sites as the displaced drug. Third, the displacer should have a high affinity for the binding sites (i.e., a low $K i$ ). And finally, the displacer should be present in large amounts relative to its $K i$ value. As demonstrated in this study, all four of these criteria appear to have been met with respect to ibuprofen enantiomers. The data are also in agreement with a previous study in four healthy male subjects where the oral clearance of $R(-)$-ibuprofen was $29 \%$ greater when administered as $800-\mathrm{mg}$ racemate than when administered alone as a $400-\mathrm{mg}$ dose (17).

A comparison of enantiomeric affinity parameters to that of ibuprofen racemate is difficult because of the different methods of analysis used by investigators $(16,18-20)$. Nevertheless, our data were remarkably close to estimates by Lockwood et al. (16) and Mills et al. (18) in which the equilibrium association constant (i.e., $K_{\mathrm{A}}=1 / P 2$, reciprocal molar units) was reported as $1.76 \times 10^{5} \mathrm{M}^{-1}$ (in vivo) and $1 \times 10^{5} \mathrm{M}^{-1}$ (in vitro), respectively. Both studies employed equilibrium dialysis at $37 \mathrm{C},{ }^{14} \mathrm{C}$-ibuprofen, and a Scatchard analysis for one class of binding sites. In contrast, Whitlam et al. (19) $\left[K_{\mathrm{A}}\right.$ of $2.73 \times 10^{6} \mathrm{M}^{-1}$ (in vitro) $]$ and Kober and Sjöholm (20) $\left[K_{\mathrm{A}}\right.$ of $1.3 \times 10^{6} \mathrm{M}^{-1}$ (in vitro) $]$ observed the affinity of ibuprofen to be approximately five to ten times greater than our values $\left[K_{\mathrm{A}}\right.$ of $5.75 \times 10^{5} \mathrm{M}^{-1}$ for $R(-)$-ibuprofen (in vivo); $2.10 \times 10^{5} \mathrm{M}^{-1}$ for $S(+)$-ibuprofen (in vivo)]. Both of these studies employed equilibrium dialysis and ${ }^{14} \mathrm{C}$-ibuprofen. However, in the one study (19), dialysis was performed on defatted solutions of human serum albumin at $37 \mathrm{C}$ and a Scatchard analysis was performed for two classes of binding sites. In the other study (20), dialysis was performed on serum samples at room temperature and a Scatchard analysis was performed for one class of binding sites. A second weaker binding site is thought not to be of any practical significance since its detection would not be revealed until very high total plasma concentrations of drug had been attained (e.g., $>140 \mu \mathrm{g} / \mathrm{ml}$ ) (18). Using fluorescence probes and dialysis methods (21) and albumin immobilized in microparticles $(20,22)$, ibuprofen has been shown to interact specifically and primarily with the diazepam binding site of human serum albumin. Our data are compatible with this finding, in which the bound-free plasma concentrations of ibuprofen enantiomers were best described by a single class of binding sites. Although one would expect the protein binding of a highly bound drug like ibuprofen to directly correlate with protein or albumin levels in plasma, our data do not show such a 
correlation. This is probably due to the homogeneous amounts of plasma proteins $(C V<6 \%)$ observed in the healthy subjects studied.

In conclusion, the plasma protein binding and competitive inhibition parameters of $R(-)$ - and $S(-)$-ibuprofen were determined in vivo in 12 healthy subjects. At therapeutic drug concentrations, the protein binding of ibuprofen enantiomers was stereoselective and mutually competitive, as well as nonlinear.

\section{ACKNOWLEDGMENT}

The authors thank Kathleen Liedholm Goldberg for her help with the clinical aspects of the study.

\section{REFERENCES}

1. S. S. Adams, P. Bresloff, and C. G. Mason. Pharmacological differences between the optical isomers of ibuprofen: evidence for metabolic inversion of the (-)-isomer. J. Pharm. Pharmacol. 28:256-257 (1976).

2. A. J. Hutt and J. Caldwell. The importance of stereochemistry in the clinical pharmacokinetics of the 2-arylpropionic acid nonsteroidal anti-inflammatory drugs. Clin. Pharmacokin. 9:371-373 (1984).

3. R. O. Day, G. G. Graham, K. M. Williams, G. D. Champion, and J. de Jager. Clinical pharmacology of non-steroidal anti-inflammatory drugs. Pharmacol. Ther. 33:383-433 (1987).

4. F. Jamali, R. Mehvar, and F. M. Pasutto. Enantioselective aspects of drug action and disposition: therapeutic pitfalls. J. Pharm. Sci. 78:695-715 (1989).

5. M. D. Murray and D. C. Brater. Nonsteroidal anti-inflammatory drugs. Clin. Geriat. Med. 6:365-397 (1990).

6. A. M. Evans, R. L. Nation, N. L. Sansom, F. Bochner, and A. A. Somogyi. Stereoselective plasma protein binding of ibuprofen enantiomers. Eur. J. Clin. Pharmacol. 36:283-290 (1989).

7. G. F. Lockwood, K. S. Albert, W. R. Gillespie, G. G. Bole, T. M. Harkcom, G. J. Szpunar, and J. G. Wagner. Pharmacokinetics of ibuprofen in man. I. Free and total area/dose relationships. Clin. Pharmacol. Ther. 34:97-103 (1983).

8. J. H. Lin, D. M. Cocchetto, and D. E. Duggan. Protein binding as a primary determinant of the clinical pharmacokinetic properties of non-steroidal anti-inflammatory drugs. Clin. Pharmacokin. 12:402-432 (1987).

9. A. M. Evans, R. L. Nation, and L. N. Sansom. Lack of effect of cimetidine on the pharmacokinetics of $R(-)$ - and $S(+)$-ibuprofen. Br. J. Clin. Pharmacol. 28:143-149 (1989).

10. A. M. Evans, R. L. Nation, L. N. Sansom, F. Bochner, and A. A. Somogyi. The relationship between the pharmacokinetics of ibuprofen enantiomers and the dose of racemic ibuprofen in humans. Biopharm. Drug Dispos. 11:507-518 (1990).

11. R. Mehvar, F. Jamali, and F. M. Pasutto. Liquid-chromatographic assay of ibuprofen enantiomers in plasma. Clin. Chem. 34:493-496 (1988).

12. M. M. Bradford. A rapid and sensitive method for the quantitation of microgram quantities of protein utilizing the principle of protein-dye binding. Anal. Biochem. 72:248-254 (1976).

13. A. Shah and D. Jung. Improved high-performance liquid chromatographic assay of ibuprofen in plasma. J. Chromatog. 344:408-411 (1985).

14. MINSQ: Nonlinear Curve Fitting and Model Development, MicroMath Scientific Software, Salt Lake City, UT, 1992. 
15. H. L. Behm and J. G. Wagner. Errors in interpretation of data from equilibrium dialysis protein binding experiments. Res. Commun. Chem. Pathol. Pharmacol. 26:145-160 (1979).

16. G. F. Lockwood, K. S. Albert, G. J. Szpunar, and J. G. Wagner. Pharmacokinetics of ibuprofen in man III: Plasma protein binding. J. Pharmacokin. Biopharm. 11:469-482 (1983).

17. E. J. D. Lee, K. Williams, R. Day, G. Graham, and D. Champion. Stereoselective disposition of ibuprofen enantiomers in man. Br. J. Clin. Pharmacol. 19:669-674 (1985).

18. R. F. N. Mills, S. S. Adams, E. E. Cliffe, W. Dickinson, and J. S. Nicholson. The metabolism of ibuprofen. Xenobiotica 3:589-598 (1973).

19. J. B. Whitlam, M. J. Crooks, K. F. Brown, and P. Veng-Pedersen. Binding of nonsteroidal anti-inflammatory agents to proteins-I. Ibuprofen-serum albumin interaction. Biochem. Pharmacol. 28:675-678 (1979).

20. A. Kober and I. Sjöholm. The binding sites on human serum albumin for some non-steroidal anti-inflammatory drugs. Mol. Pharmacol. 18:421-426 (1980).

21. G. Sudlow, D. J. Birkett, and D. N. Wade. Further characterization of specific drug binding sites on human serum albumin. Mol. Pharmacol. 12:1052-1061 (1976).

22. I. Sjöholm, B. Ekman, A. Kober, I. Ljungstedt-Påhlman, B. Seiving, and T. Sjödin. Binding of drugs to human serum albumin: XI. The specificity of three binding sites as studied with albumin immobilized in microparticles. Mol. Pharmacol. 16:767-777 (1979). 